\title{
Functional Heterogeneity of Immune Complexes in Epidermolysis Bullosa Acquisita
}

\author{
W. Ray Gammon, M.D., and Robert A. Briggaman, M.D. \\ Department of Dermatology, University of North Carolina School of Medicine, Chapel Hill, North Carolina, U.S.A.
}

Epidermolysis bullosa acquisita is an inflammatory subepidermal bullous disease characterized by circulating and tissue-bound complement-binding anti-basement membrane zone autoantibodies to type VII procollagen. Lesions are characterized by neutrophil-predominant inflammation in some patients, but not in others. These features suggest complement activation and generation of complement-derived chemotactic factors for leukocytes by basement membrane zone immune complexes may contribute to inflammation, but that complexes may be heterogeneous in the ability to express that function. In this study, we measured the ability of basement membrane zone complexes from patients with $(\mathrm{n}=4)$ and without $(\mathrm{n}=6)$ neutrophil predominant inflammation to activate complement and generate complement-derived chemotactic activity using a complement-dependent neutrophil attachment assay. The results showed considerable heterogeneity in neutrophil attachment among EBA patients and that both the incidence (4/4 vs $2 / 6)$ and magnitude $(81 \pm 34$ vs $12 \pm 10$ neutrophils $/ \mathrm{mm}$ basement membrane zone) of attachment were greater in patients with neutrophil-predominant inflammation. Functional heterogeneity appeared to be due to differences in the amounts of complement-activating complexes formed at the basement membrane zone, which in turn appeared to be due to differences in the availability of circulating complement-binding anti-basement membrane zone antibodies. This was suggested by a positive correlation $(r=0.72, p<0.01)$ between neutrophil attachment and complement-binding anti-basement membrane zone antibody titers and the observation that high levels of neutrophil attachment could be generated in skin from patients with epidermolysis bullosa acquisita who did not have neutrophil-predominant inflammation by treating their skin in vitro with complement-binding anti-basement membrane zone antibodies. These results suggest tissue complexes in epidermolysis bullosa acquisita are heterogeneous in the ability to activate complement and generate complementderived chemotactins (C5a, C5a des arg), and that functional heterogeneity contributes to histologic heterogeneity. The functional immunologic-pathologic correlations observed in this study suggest epidermolysis bullosa acquisita is an autoimmune "collagen" disease. I Invest Dermatol 89:478-483, 1987

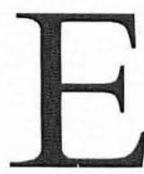

pidermolysis bullosa acquisita (EBA) is a chronic blistering disease of skin and mucous membranes with distinctive clinical, pathologic, and immunologic features. Although there are diagnostic features shared by all patients, there is considerable variation in the

Manuscript received February 17, 1987; accepted for publication April 23, 1987.

This work was supported by National Institutes of Health Research Career Development Award grant AM00956, CRU grant RR00046, and NIH grants AR30475 and AM10546.

Reprints requests to: W. R. Gammon, M.D., Department of Dermatology, University of North Carolina School of Medicine, 137 North Carolina Memorial Hospital, Chapel Hill, NC 27514

Abbreviations:

BMZ: basement membrane zone

C: complement

EBA: epidermolysis bullosa acquisita

FITC: fluorescein isothiocyanate

GBSS: Gey's balanced salt solution

$\mathrm{H} \& \mathrm{E}$ : hematoxylin and eosin

IgG: immunoglobulin $G$

$N$ : number of samples

NA: neutrophil attachment

NHS: normal human serum

PBS: phosphate-buffered saline

SEM: standard error of the mean clinical and pathologic features among patients. This variability is expressed in part by the presence or absence of clinical signs of inflammation and by the degree and type of inflammation in lesions.

The disease is also characterized by the in situ formation of immune complexes at the cutaneous basement membrane zone (BMZ). These complexes have been characterized by immunohistologic, immunoultrastructural, and immunochemical methods and shown to consist of a BMZ matrix molecule (EBA antigen), and an anti-BMZ autoantibody (EBA antibody). Recent studies have shown that the EBA antigen is type VII procollagen.

Several lines of evidence suggest these complexes may activate the complement (C) system and that immune complex-mediated $\mathrm{C}$ activation and generation of C-derived mediators may contribute to inflammation and blisters in some patients. Direct and indirect C-binding immunofluorescence studies have shown that $\mathrm{C}$ proteins are deposited at the $\mathrm{BMZ}$ in vivo in virtually all patients, and that EBA antibodies capable of binding $C$ at the $\mathrm{BMZ}$ in vitro are present in the circulation in some patients. Furthermore, the inflammatory infiltrate in the lesions of some patients is neutrophil predominant and analogous to that which has been reported in experimental models of immune complexand C-mediated inflammation.

In previous studies, we showed that $\mathrm{C}$-binding EBA antibodies could bind to the BMZ of normal human skin in organ culture and form $\mathrm{C}$-activating immune complexes that could mediate C- 
dependent leukocyte migration and injury to the BMZ. Furthermore, we showed that complexes in the skin of patients with circulating C-binding EBA antibodies and neutrophil-predominant inflammation could activate $\mathrm{C}$ in vitro and generate $\mathrm{C}$-derived chemotactic activity for leukocytes.

It is apparent from these studies that immune complexes in the skin of some patients can activate $C$ and generate $C$-derived mediators of inflammation; however, it is not known if this is true in all patients. Not all patients have circulating C-binding EBA antibodies and not all have neutrophil-predominant inflammation. Studies of this question could lead to a better understanding of the role of immune complexes in the pathogenesis of skin lesions and the relationship between immune complex function and the variable clinical and histologic features of the disease.

In this study, we have examined the question by measuring the extent to which complexes in the skin of 10 EBA patients with and without neutrophil-predominant inflammation can activate $\mathrm{C}$ and generate $\mathrm{C}$-derived chemotactic activity for leukocytes. This function was measured using the C-dependent neutrophil attachment (NA) assay. The results show there is considerable heterogeneity in the extent to which complexes from different patients mediate C-dependent NA. Furthermore, they show that this function is more often expressed and expressed to a greater magnitude in patients with neutrophil-predominant inflammation. Differences in the extent to which complexes expressed the function appeared to be due to the amount of $\mathrm{C}$ activating immune complexes formed at the $\mathrm{BMZ}$ in vivo which in turn appeared to be determined by the availability of $\mathrm{C}$-binding EBA antibody. This was suggested by the finding of a significant positive correlation between titers of $\mathrm{C}$-binding EBA antibodies and $\mathrm{C}$-dependent NA and by the finding that treatment of skin having intrinsically low C-dependent NA activity with serum having high titer C3-binding EBA antibodies resulted in the formation of complexes with high activity.

These results show there is functional heterogeneity in EBA immune complexes, suggest it is due to the availability of Cbinding EBA antibodies and suggest it may contribute to heterogeneity in the clinical and histologic features of the disease. Furthermore, these results provide additional evidence that EBA is in part an immune complex-mediated autoimmune bullous disease.

\section{MATERIALS AND METHODS}

Patients Tissue and sera were obtained from 10 patients with EBA seen in the Department of Dermatology, UNC School of Medicine. All patients were evaluated by both authors, and diagnostic studies were performed by the authors in conjunction with members of the Department of Pathology, UNC School of Medicine. The diagnosis was made in all patients on the basis of previously published clinical, histologic, immunohistologic, and immunoultrastructural criteria [1]. Seven patients had circulating anti-BMZ antibodies, and all of these antibodies had the specific immunohistologic, immunoultrastructural, and immunochemical features of EBA antibodies [2,3].

Skin and Sera Skin and sera were obtained from all patients at their initial clinic visit. Four-millimeter punch biopsies of early blisters and adjacent clinically normal appearing perilesional skin were obtained under local $1 \%$ xylocaine anesthesia. Normal human skin was obtained from fresh surgical specimens by keratome. Lesional skin was immediately fixed in formalin. Perilesional and portions of normal human skin were immediately snap frozen in liquid $\mathrm{N}_{2}$, mounted in OCT compound (Miles Laboratory Inc, Naperville, Illinois), and stored frozen at $-70^{\circ} \mathrm{C}$. Some portions of normal human skin were first separated through the lamina lucida as previously described, washed in $0.1 \mathrm{M} \mathrm{NaCl}$ buffered with $0.01 \mathrm{M} \mathrm{Na}_{2} \mathrm{HPO}_{4}, 0.01 \mathrm{M} \mathrm{NaH}_{2} \mathrm{PO}_{4}, \mathrm{pH} 7.2$ (PBS), mounted in OCT compound, and stored frozen at $-70^{\circ} \mathrm{C}$. Patients' sera were obtained at the time of biopsy and heat inactivated at $56^{\circ} \mathrm{C}$ for $30 \mathrm{~min}$ just before use. Platelet-poor normal human serum (NHS) was obtained from a single blood group type AB, $\mathrm{Rh}^{+}$donor as previously described [4] and aliquoted. Some aliquots were heat inactivated just before use. All sera were stored frozen at $-70^{\circ} \mathrm{C}$.

Peripheral Blood Neutrophils (PBN) Normal human PBN were obtained from a single donor as follows: Peripheral blood leukocytes were obtained by mixing $25 \mathrm{ml}$ of heparinized blood (100 units beef lung heparin $/ 5 \mathrm{ml}$ blood) with $10 \mathrm{ml}$ of Plasmagel (Cellular Products Inc., Buffalo, New York) and allowing it to gravity sediment at $25^{\circ} \mathrm{C}$ for $60 \mathrm{~min}$. The leukocyte rich supernatant was centrifuged at $200 \mathrm{~g}$ and the pellet resuspended in 4.0 $\mathrm{ml}$ of normal saline. The suspension was layered over $3.0 \mathrm{ml}$ of a solution containing Ficoll (Sigma Chemical Co., St. Louis, Missouri) and Hypaque (Winthrop-Breon Laboratories, New York, New York) in distilled $\mathrm{H}_{2} \mathrm{O}$ (specific gravity $=1.15-1.17$ ) and centrifuged at $300 \mathrm{~g}$ for $35 \mathrm{~min}$ at $25^{\circ} \mathrm{C}$. The pellet containing greater than $95 \%$ viable neutrophils was washed twice in Geys balanced salt solution (GBSS) containing $2.0 \%$ bovine serum albumin (Flow Laboratories, McLean, Virginia) and adjusted to a concentration of $24 \times 10^{6}$ cells/ml GBSS.

Immunoreagents Fluorescein isothiocyanate (FITC)-conjugated IgG fractions of goat antisera to human $\operatorname{IgG}$ and the third component of C (C3) were purchased from Cooper Biomedical Inc., Malvern, Pennsylvania. Molar fluorescein to protein ratios and specific antibody concentrations were: antihuman $\operatorname{IgG}(2.8$, $3.0 \mathrm{mg} / \mathrm{ml})$, antihuman $\mathrm{C} 3(3.0,3.4 \mathrm{mg} / \mathrm{ml})$. Conjugates were used diluted 1:40-1:80 in PBS plus $0.02 \% \mathrm{NaN}_{3}$.

Histology and Immunofluorescence Routine hematoxylin and eosin (H\&E)-stained slides of lesional skin were prepared and read by members of the Department of Pathology without knowledge of the diagnosis. All slides were also read by one or both authors. Direct immunofluorescence for IgG and C3 was performed on perilesional EBA skin as previously described [5]. Intensity of fluorescence staining was graded as: 0 , absent; $1+$, faint; $2+$, moderate; $3+$, bright. Titers of $\operatorname{Ig} G$ and C3-binding EBA antibodies were determined by indirect IgG and C3-binding immunofluorescence using $\mathrm{NaCl}$-separated normal human skin as substrate and previously described methods [2,5].

C-Dependent NA Assay Neutrophil attachment assays were performed using a modification of the previously described leukocyte attachment assay $[4,6]$. Briefly, four to five $8-\mu \mathrm{m}$ thick cryostat sections of fresh frozen perilesional skin were placed in the center of gelatin-coated glass slides. Some sections were incubated for $30 \mathrm{~min}$ at $4^{\circ} \mathrm{C}$ with $25 \mu \mathrm{l} /$ section of a $1: 10$ dilution (PBS) of serum containing high titer $(1: 160)$ C3-binding EBA antibodies or NHS. Sections were washed $5 \mathrm{~min}$ four times in PBS and blotted to remove excess moisture. Serum-treated and untreated sections were covered with a second slide and attachment chambers constructed. Chambers were filled $(0.3 \mathrm{ml})$ with $12 \times 10^{6} \mathrm{PBN} / \mathrm{ml}$ plus either $10 \%$ NHS or $10 \%$ heat-inactivated NHS, incubated for $45 \mathrm{~min}$ at $37^{\circ} \mathrm{C}$ in a moist air atmosphere, disassembled and sections washed in PBS to remove serum and nonadherent cells. Sections were briefly air dried, fixed in ethanol, stained with $\mathrm{H} \&$ E and examined with a light microscope equipped with a rotating linear micrometer eyepiece. Neutrophils attached at the BMZ were counted in three consecutive 1-mm segments of BMZ in each of three randomly chosen sections on each slide and an average number of neutrophils $/ \mathrm{mm} \mathrm{BMZ}$ calculated. For each biopsy, a mean NA/mm BMZ in the presence of NHS (NA with $\mathrm{C}$ ) and heat-inactivated NHS (NA without C) was calculated from simultaneous assays performed in triplicate. Complement dependent NA was calculated for each biopsy by subtracting NA without $C$ from NA with $C$. Results were expressed as C-dependent NA \pm SEM for triplicate assays.

Statistical Analysis Data were evaluated for statistical significance using the Student $t$ test and coefficient of correlation. 


\section{RESULTS}

Histology of EBA Lesions Hematoxylin and eosin-stained sections of biopsies from early blisters were examined by members of the Department of Pathology and one or both authors. There was complete agreement between observers on the type of inflammation in lesions from all 10 patients. In most biopsies, there was a mixture of mononuclear cells and granulocytes in the upper dermis and at the BMZ but in all except one, a predominant cell type was present (Table I). In four patients (Ma, Co, Ki, Ha) there was a moderate to dense accumulation of leukocytes predominantly consisting of neutrophils. In five patients (McC, Mac, $\mathrm{Go}, \mathrm{Bo}, \mathrm{El})$ there was a sparse to moderately dense accumulation of cells predominantly composed of mononuclear cells. In one patient (Ca) there was a moderately dense accumulation of leukocytes consisting of approximately equal numbers of mononuclear cells and eosinophils. In lesions in which neutrophils predominated, mononuclear cells were also seen and in most of these a few eosinophils were also present. In 2 of 6 cases with mononuclear cell predominance, no neutrophils were seen.

Immunohistology of Perilesional EBA Skin The results of direct IgG and C3 immunofluorescence of perilesional skin are shown in Table I. All patients had IgG and C3 deposits at the BMZ. The intensity of staining for IgG ranged from $2-3+$. The intensity of $\mathrm{C} 3$ staining ranged from $1-3+$. There did not appear to be a significant difference in the intensity of $\operatorname{IgG}$ or C3 staining among patients with and without neutrophil predominant inflammation.

Titers of $\mathrm{IgG}$ and C3-Binding EBA Antibodies in EBA Sera Titers of IgG and C3-binding EBA antibodies in patients' sera are shown in Table I. IgG EBA antibodies were detected in 7 of 10 patients and ranged in titer from 40-640. C3-binding EBA antibodies were detected in 6 of 10 patients and titers ranged from 40-160. In no case were C3 binding EBA antibodies detected in patients without IgG EBA antibodies.

Complement-Dependent Neutrophil Attachment in Perilesional EBA Skin The results of NA with C, NA without $\mathrm{C}$, and $\mathrm{C}$-dependent NA in perilesional EBA skin are shown in Table II and Fig 1. The results showed that C-dependent NA ranged from less than $0-115 \pm 11$ cells $/ \mathrm{mm} \mathrm{BMZ}$. C-dependent NA ranging from $24 \pm 4$ to $115 \pm 11$ cells $/ \mathrm{mm} \mathrm{BMZ}$ could be detected in six patients ( $\mathrm{Ma}, \mathrm{Co}, \mathrm{Ki}, \mathrm{Ha}, \mathrm{McC}$ and $\mathrm{Bo}$ ). No significant $\mathrm{C}$-dependent attachment could be detected in four patients (Mac, Ca, Go, El).

Relationship Between C-Dependent NA and Neutrophil Predominant Inflammation in EBA A comparison of the histologic findings in lesional EBA skin and the results of Cdependent NA in adjacent perilesional skin showed that $\mathrm{C}$-dependent NA ranging from $47 \pm 21$ to $115 \pm 11$ cells $/ \mathrm{mm} \mathrm{BMZ}$ was present in the four patients with neutrophil-predominant inflammation. Of six patients without neutrophil-predominant inflammation, only two had detectable levels of C-dependent NA. In these two patients, C-dependent NA values $(24 \pm 4$ and 29 \pm 4 cells $/ \mathrm{mm}$ BMZ) were less than those in any of the four patients with neutrophil-predominant inflammation. The mean value for $\mathrm{C}$-dependent NA, in four patients with neutrophilpredominant inflammation, $81 \pm 34$ cells $/ \mathrm{mm}$ BMZ was significantly greater $(p<0.01)$ than that $(12 \pm 10$ cells $/ \mathrm{mm} \mathrm{BMZ})$ in six patients without neutrophil-predominant inflammation (Fig 2).

Relationship Between C-Dependent NA and Titers of C3Binding EBA Antibodies To determine if a relationship existed between C-dependent NA and titers of circulating C3-binding EBA antibodies, the results of these assays were tested for correlation. The results, depicted graphically in Figure 3, showed a significantly positive correlation $(r=0.72 ; p<0.01)$ between levels of $\mathrm{C}$-dependent NA and titers of C3-binding EBA antibodies.

Effect of C3-Binding EBA Antibodies on C-Dependent NA in EBA Skin Sections of perilesional skin from two patients (Mac, El) without neutrophil-predominant inflammation and low C-dependent NA, and one patient $\mathrm{Ma}$, with neutrophil-predominant inflammation and high NA were treated with a serum having high titer C3-binding EBA antibodies or NHS as control and the C-dependent NA assay repeated. The results, Table III, showed that treatment of skin from EBA patients without neutrophilpredominant inflammation and low $\mathrm{C}$-dependent NA with high titer C-binding EBA antibodies caused a significant increase in NA $(-23 \pm 16$ to $81 \pm 2$ and $0 \pm 4$ to $104 \pm 13$ cells $/ \mathrm{mm}$ $\mathrm{BMZ})$. The treatment caused no significant change in activity $(115 \pm 11$ to $122 \pm 6$ cells $/ \mathrm{mm}$ BMZ) in skin from the patient with neutrophil-predominant inflammation and high $\mathrm{C}$-dependent NA activity.

\section{DISCUSSION}

Epidermolysis bullosa acquisita is a chronic disease defined by its clinical, histologic, and immunologic features [1]. Clinical features include skin fragility, blisters and erosions of skin and mucous membranes, and a tendency for lesions to heal with scarring. Histologic features include a subepidermal blister and inflammation in the upper dermis and at the BMZ. Immunologic features include linear deposits of $\operatorname{IgG}$ and $C$ proteins at the BMZ and circulating EBA antibodies.

Epidermolysis bullosa acquisita antibodies have been shown to have immunoultrastructural and antigen specificity properties that differ from IgG anti-BMZ autoantibodies in all other primary bullous diseases, except bullous eruption of systemic lupus erythematosus [7]. By immunoelectron microscopy, they bind on and just beneath the lamina densa $[1,2]$. By immunoblotting

Table I. Histologic, Immunohistologic, and Serologic Features of Patients With EBA

\begin{tabular}{|c|c|c|c|c|c|}
\hline \multirow{2}{*}{ Patient } & \multirow{2}{*}{$\begin{array}{l}\text { Lesion Histology } \\
\text { Predominant leukocyte }\end{array}$} & \multicolumn{2}{|c|}{$\begin{array}{c}\text { Direct } \\
\text { Immunofluorescence }\end{array}$} & \multicolumn{2}{|c|}{ EBA Antibodies (titers) } \\
\hline & & $\operatorname{IgG}$ & C3 & $\operatorname{Ig} G$ & C3 Binding \\
\hline Man & N & $3+$ & $3+$ & 160 & 80 \\
\hline $\mathrm{Co}$ & $N$ & $3+$ & $2+$ & 640 & 160 \\
\hline $\mathrm{Ki}$ & $N$ & $3+$ & $3+$ & 320 & 160 \\
\hline $\mathrm{Ha}$ & $N$ & $3+$ & $3+$ & 160 & 40 \\
\hline $\mathrm{McC}$ & $\mathrm{M}$ & $3+$ & $3+$ & 640 & 40 \\
\hline $\mathrm{Mac}$ & $M$ & $2+$ & $1+$ & 40 & 40 \\
\hline Go & M & $2+$ & $2+$ & 0 & 0 \\
\hline $\mathrm{Ca}$ & $\mathrm{M} / \mathrm{E}$ & $3+$ & $3+$ & 0 & 0 \\
\hline Bo & $M$ & $3+$ & $2+$ & 0 & 0 \\
\hline El & $M$ & $2+$ & $2+$ & 40 & 0 \\
\hline
\end{tabular}


Table II. Neutrophil Attachment in EBA Biopsies

\begin{tabular}{cccc}
\hline Patient & NA with NHS $( \pm$ SEM) & NA without NHS $( \pm$ SEM $)$ & C Dependent NA $( \pm$ SEM) \\
\hline Man & $188 \pm 16$ & $73 \pm 8$ & $115 \pm 11$ \\
Co & $158 \pm 8$ & $111 \pm 8$ & $47 \pm 16$ \\
Ki & $65 \pm 5$ & $114 \pm 26$ \\
$\mathrm{Ha}$ & $179 \pm 23$ & $105 \pm 8$ & $47 \pm 21$ \\
$\mathrm{McC}$ & $86 \pm 3$ & $62 \pm 5$ & $24 \pm 4$ \\
$\mathrm{Mac}$ & $47 \pm 8$ & $69 \pm 7$ & $-23 \pm 11$ \\
$\mathrm{Go}$ & $69 \pm 9$ & $75 \pm 7$ & $-6 \pm 13$ \\
$\mathrm{Ca}$ & $44 \pm 9$ & $39 \pm 11$ & $5 \pm 10$ \\
$\mathrm{Bo}$ & $60 \pm 8$ & $38 \pm 4$ & $29 \pm 4$ \\
$\mathrm{El}$ & $31 \pm 5$ & $31 \pm 10$ & $0 \pm 5$ \\
\hline
\end{tabular}

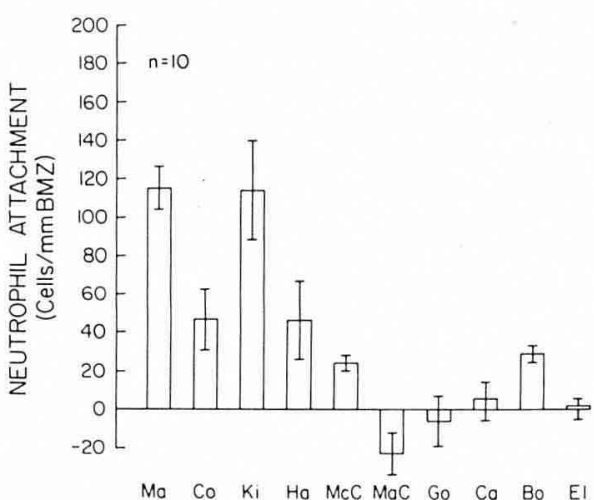

Figure 1. Complement-dependent neutrophil attachment in EBA. The figure shows the heterogeneity of complement-dependent neutrophil attachment levels in 10 patients with EBA (Ma-E1).

methods, they react with a unique collagenase sensitive, $290 \mathrm{kD}$ glycoprotein that is a normal component of basement membranes of stratified squamous epithelium $[3,8,9]$. Recently this collagenase sensitive glycoprotein has been identified as type VII procollagen [10].

In recent years, it has become apparent that patients with the immunologic features of EBA have variable clinical and histologic features $[11,12]$. In some patients lesions are mainly trauma induced, localized to trauma-susceptible extensor skin surfaces, heal with scarring and milia, and are unaccompanied by clinical signs of inflammation such as erythema. Dermal inflammation in these patients is relatively sparse and mainly composed of mononuclear cells. In other patients, blisters often appear spontaneously, are

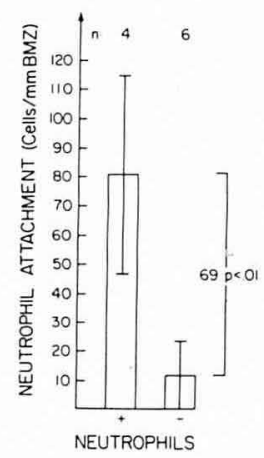

Figure 2. Complement-dependent neutrophil attachment levels in EBA patients with and without neutrophil-predominant inflammation. The bars represent the mean complement-dependent neutrophil attachment levels in four patients with EBA with $(+)$ and six patients without (-) neutrophil-predominant inflammation.
Table III. C-Dependent Neutrophil Attachment: Effect of Pretreating Skin with C-Binding EBA Antibodya

\begin{tabular}{lccc}
\hline & \multicolumn{3}{c}{$\begin{array}{c}\text { Complement-Dependent Neutrophil Attachment } \\
\text { (Cells/mm BMZ } \pm \text { SD) }\end{array}$} \\
\cline { 2 - 4 } & $\begin{array}{c}\text { Without } \\
\text { Antibody }\end{array}$ & $\begin{array}{c}\text { With } \\
\text { Antibody }\end{array}$ & $\begin{array}{c}\text { With Normal } \\
\text { Human Serum }\end{array}$ \\
\hline Mac & $-23 \pm 16$ & $81 \pm 2$ & $-4 \pm 6$ \\
El & $0 \pm 4$ & $104 \pm 13$ & $13 \pm 4$ \\
$\mathrm{Ma}$ & $115 \pm 11$ & $122 \pm 6$ & $118 \pm 3$ \\
\hline
\end{tabular}

"Skin was treated with C-binding EBA antibody or normal human serum (control) diluted $1: 10$ in PBS-NaNz. 1

more generalized, involve flexural as well as extensor surfaces, may heal without scarring, and are usually accompanied by erythema. Inflammation in these patients is moderate to dense, and predominantly consists of neutrophils. The reasons for these differences among patients are unknown. Although factors such as age, location, or type of lesion biopsied may contribute to differences in the type and degree of inflammation, it is possible that quantitative or qualitative differences in the factor(s) responsible for leukocyte recruitment play a role.

One of the factors that may contribute to leukocyte recruitment in EBA is immune complex-mediated $\mathrm{C}$ activation and generation of C-derived chemotactic activity at the BMZ. Some patients are characterized by neutrophil-predominant inflammation, which is the type of inflammation usually seen in experimental models of immune complex and C-mediated tissue injury [13-15], and the type of inflammatory response seen in dermis treated with the purified C-derived chemotactic peptides, C5a and C5a des arg [16-18]. In previous studies, we showed that immune complexes formed by treating normal human skin with C3-binding

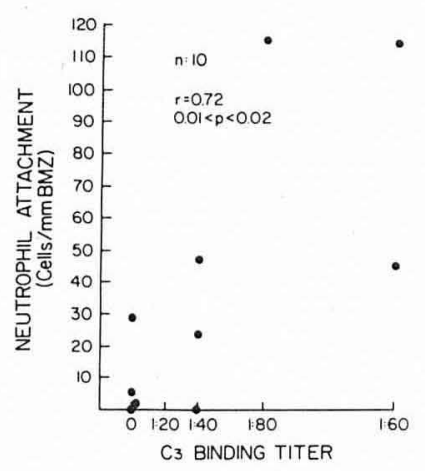

Figure 3. Neutrophil attachment vs C3-binding titers. The figure shows the relationship between $\mathrm{C}$-dependent neutrophil attachment and C3binding EBA antibody titers in 10 patients with EBA. 
EBA antibodies in organ culture could mediate C-dependent leukocyte migration and injury to the BMZ [19]. We also showed that tissue immune complexes from patients with circulating C3binding EBA antibodies and neutrophil-predominant inflammation could activate $\mathrm{C}$ and generate $\mathrm{C}$-dependent chemotactic activity for leukocytes in vitro [19].

The fact that not all patients have inflammation characteristic of immune complex-mediated $\mathrm{C}$ activation suggested that immune complexes among patients with EBA might not activate $\mathrm{C}$ and generate $\mathrm{C}$-derived chemotactic activity to the same degree. In this study, we examined that hypothesis by measuring Cdependent NA at the BMZ mediated by immune complexes in the skin of patients with EBA with and without neutrophil-predominant inflammation. The method used was a modification of the previously described and characterized C-dependent leukocyte attachment assay, which has been shown to indirectly detect and measure $\mathrm{C}$ activation and generation of C-derived chemotactic activity by immune complexes formed at the $\mathrm{BMZ}$ in vitro and in vivo $[4,6]$. The modification involved the use of relatively pure populations of neutrophils as indicator cells. This was done to further standardize the assay and because neutrophils are among the most responsive cells to $\mathrm{C}$-derived chemotactic factors.

The results showed that $\mathrm{C}$-dependent NA to the BMZ varied among patients and ranged from undetectable to more than 100 cells/mm BMZ. Activity ranging from 24 to 115 cells $/ \mathrm{mm} \mathrm{BMZ}$ was detected in six patients and no activity was detected in four others. The absence of activity in these cases was not due to the absence of complexes since all biopsies showed IgG deposits by direct immunofluorescence. The results also showed a relationship between neutrophil-predominant inflammation and both the presence and degree of C-dependent NA. All four patients with neutrophil predominant inflammation had detectable C-dependent NA ranging from 47 to 115 cells $/ \mathrm{mm}$ BMZ. Only two of six patients without neutrophil-predominant inflammation had detectable C-dependent NA. Furthermore, C-dependent NA in those two patients ( 24 and 29 cells/mm BMZ) was less than that measured in any patient with neutrophil-predominant inflammation.

Another question addressed in this study was why there are differences in the ability of EBA complexes to mediate C-dependent NA. Possibilities could include differences in the amounts of C-activating complexes present at the $\mathrm{BMZ}$ or differences in the efficiency with which they activate $\mathrm{C}$ and/or generate chemotactic factors. Since methods for measuring efficiency of C activation by tissue complexes have not been described, we could only address the first possibility. This was done by pretreating EBA skin having low or absent intrinsic C-dependent NA with serum containing high titer C3-binding EBA antibodies. This treatment generated significant increases in C-dependent NA in biopsies with low intrinsic activity but had little effect on the biopsy with high intrinsic activity. The increase in neutrophil attachment appeared to be due to C3-binding EBA antibody since treatment with serum containing non-C3 binding EBA antibody did not cause neutrophil attachment (unpublished observations). This finding suggests the differences in C-dependent NA among patients with EBA are due, at least in part, to differences in the amount of C-activating complexes present at the BMZ. It also suggests that differences in the amount of these complexes is due to differences in the availability of C-binding EBA antibodies, and not to any limitation in the availability of EBA antigen. Had there been limited antigen, it would not have been possible for the addition of exogenous antibody to form complexes capable of generating C-dependent NA. The question of limited antigen as a cause of low NA is an important one since it is now apparent that type VII procollagen is a component of anchoring fibrils and electron microscopic studies of EBA skin have reported decreased numbers of anchoring fibrils in some patients [20].

Limited availability of C-binding EBA antibody and not antigen as a cause of low or absent C-dependent NA was also suggested by the significantly positive correlation between levels of C-dependent NA and titers of circulating C3-binding EBA antibodies. This finding suggests the amount of $\mathrm{C}$-activating complexes at the BMZ is in equilibrium with the amount of $\mathrm{C}$ activating antibody in the circulation. Exceptions to the correlation between C-dependent NA and titers of C3-binding antibody were seen in two patients. In one, C-dependent NA was detected and C3-binding antibodies were not. In the other C3binding antibodies were detected but C-dependent NA was not. The reasons for these discrepancies are not known but there are several possibilities. In the first case, it is possible that the C3binding antibodies were of unusually high affinity and absorbed to the BMZ before serum levels could be detected or that they had been in the circulation, formed a persistent and stable complex at the BMZ and disappeared from the circulation before serum was sampled. In the second case, non-C3 binding antibodies could have competed with C3-binding antibodies for available EBA antigen and interfered with the formation of C-activating complexes.

The results of this study have several important implications regarding immune complex function in EBA. First, they show there is heterogeneity in the ability of EBA immune complexes to mediate C-dependent NA. This strongly suggests that tissue complexes in EBA patients are functionally heterogeneous in their ability to activate the $\mathrm{C}$ system and generate the $\mathrm{C}$-derived chemotactic factors, C5a/C5a des arg. Second, the relationship between C-dependent NA and the type of inflammation in these patients suggests that immune complex-mediated $\mathrm{C}$ activation influences the inflammatory response in lesions and that neutrophil-predominant inflammation results in part from immune complex-mediated $\mathrm{C}$ activation. Third, they suggest that either quantitative differences in immune complex-mediated C activation influence differences in the inflammatory response or that in some patients, other mechanisms are responsible for leukocyte recruitment. Although six patients in this study did not have neutrophil-predominant inflammation, it is still possible that immune complex-mediated $\mathrm{C}$ activation played a role in the pathogenesis of their lesions. Two patients had detectable C-dependent NA. Although four patients did not, it is possible the assay was insufficiently sensitive to detect activity or that the activity of complexes in tissue that was assayed was not representative of immune complex activity in lesional skin. The fact that monocytes were the predominant cells in lesions from these patients does not exclude a role for $\mathrm{C}$-derived chemotactic factors in their recruitment, since monocytes have been shown to respond to these factors in vitro $[21,22]$.

\section{REFERENCES}

1. Briggaman RA, Gammon WR, Woodley DT: Epidermolysis bullosa acquisita of the immunopathological type (dermolytic pemphigoid). J Invest Dermatol 85(suppl):79s-84s, 1985

2. Gammon WR, Briggaman RA, Inman AO III, Queen LL, Wheeler CE: Differentiating anti-lamina lucida and anti-sublamina densa anti-BMZ antibodies by indirect immunofluorescence on $1.0 \mathrm{M}$ sodium chloride-separated skin. J Invest Dermatol 82:139-144, 1984

3. Woodley DT, Briggaman RA, O'Keefe EJ, Inman AO, Queen LL, Gammon WR: Identification of the skin basement-membrane autoantigen in epidermolysis bullosa acquisita. N Engl J Med 310: 1007-1013, 1984

4. Gammon WR, Lewis DM, Carlo JR, Sams WM Jr, Wheeler CE Jr: Pemphigoid antibody mediated attachment of peripheral blood leukocytes at the dermal-epidermal junction of human skin. J Invest Dermatol 75:334-339, 1980

5. Carlo JR, Gammon WR, Sams WM Jr, Ruddy S: Demonstration of the complement regulating protein, $\mathrm{B} 1 \mathrm{H}$, in skin biopsies from patients with bullous pemphigoid. J Invest Dermatol 73:551-553, 1979

6. Gammon WR, Merritt CC, Lewis DM, Sams WM Jr, Wheeler CE Jr, Carlo J: Leukocyte chemotaxis to the dermal-epidermal junction of human skin mediated by pemphigoid antibody and complement: mechanism of cell attachment in the in vitro leukocyte attachment method. J Invest Dermatol 76:514-522, 1981 
7. Gammon WR, Woodley DT, Dole KC, Briggaman RA: Evidence that anti-basement membrane zone antibodies in bullous eruption of systemic lupus erythematosus recognize epidermolysis bullosa acquisita autoantigen. J Invest Dermatol 84:472-476, 1985

8. Woodley DT, O'Keefe EJ, Reese MJ, Mechanic GL, Briggaman RA, Gammon WR: Epidermolysis bullosa acquisita antigen, a new major component of cutaneous basement membrane, is a glycoprotein with collagenous domains. J Invest Dermatol 86:668-672, 1986

9. Paller AS, Queen LL, Woodley DT, Lane AT, Gammon WR, Briggaman RA: Organ-specific, phylogenetic, and ontogenetic distribution of the epidermolysis bullosa acquisita antigen. J Invest Dermatol 86:376-379, 1986

10. Woodley DT, Burgeson RE, Lunstrum GP, Reese MJ, BrucknerTuderman L, Gammon WR, Briggaman RA: The epidermolysis bullosa acquisita antigen is type VII procollagen. Clin Res, 35: 726A, 1987

11. Gammon WR, Briggaman RA, Wheeler CE Jr: Epidermolysis bullosa acquisita presenting as an inflammatory bullous disease. J Am Acad Dermatol 7:382-387, 1982

12. Gammon WR, Briggaman RA, Woodley DT, Heald PW, Wheeler CE Jr: Epidermolysis bullosa acquisita-a pemphigoid-like disease. J Am Acad Dermatol 11:820-832, 1984

13. Cochrane CG, Unanue ER, Dixon FJ: A role of polymorphonuclear leukocytes and complement in nephrotoxic nephritis. J Exp Med 122:99-116, 1965

14. Kniker WT, Cochrane CG: Pathogenic factors in ascular lesions of experimental serum sickness. J Exp Med 122:83-97, 1965
15. DeShazo CV, Henson PM, Cochrane CG: Acute immunologic arthritis in rabbits. J Clin Invest 51:50-57, 1972

16. Fernandez HN, Henson PM, Otani A, Hugli TE: Chemotactic response to human $\mathrm{C} 3 \mathrm{a}$ and $\mathrm{C} 5 \mathrm{a}$ anaphylatoxins. I. Evaluation of $\mathrm{C} 3 \mathrm{a}$ and $\mathrm{C} 5 \mathrm{a}$ leukotaxis in vitro and under simulated in vivo conditions. J Immunol 120:109-115, 1978

17. Gerard C, Chenoweth DE, Hugli TE: Response of human neutrophils to C5a: a role for the oligosaccharide moiety of human $\mathrm{C} 5 \mathrm{a}_{\mathrm{dcs}}$ Arg-74 but not of C5a in biologic activity. J Immunol 127:1978-1982, 1981

18. Yancey KB, Hammer CH, Harvath L, Renfer L, Frank MM, Lawley TJ: Studies of human C5a as a mediator of inflammation in normal human skin. J Clin Invest 75:486-495, 1985

19. Gammon WR, Inman AO III, Wheeler CE Jr: Differences in complement-dependent chemotactic activity generated by bullous pemphigoid and epidermolysis bullosa acquisita immune complexes: demonstration by leukocytic attachment and organ culture methods. J Invest Dermatol 83:57-61, 1984

20. Yaoita H, Briggaman RA, Lawley TJ, Provost TT, Katz SI: Epidermolysis bullosa acquisita: ultrastructural and immunological studies. J Invest Dermatol 76:288-292, 1981

21. Ward PA: Chemotaxis of mononuclear cells. J Exp Med 128:1201-1221, 1968

22. Snyderman R, Shin HS, Hausman MH: A chemotactic factor for mononuclear leukocytes. Proc Soc Exp Biol Med 138:387-390, 1971 